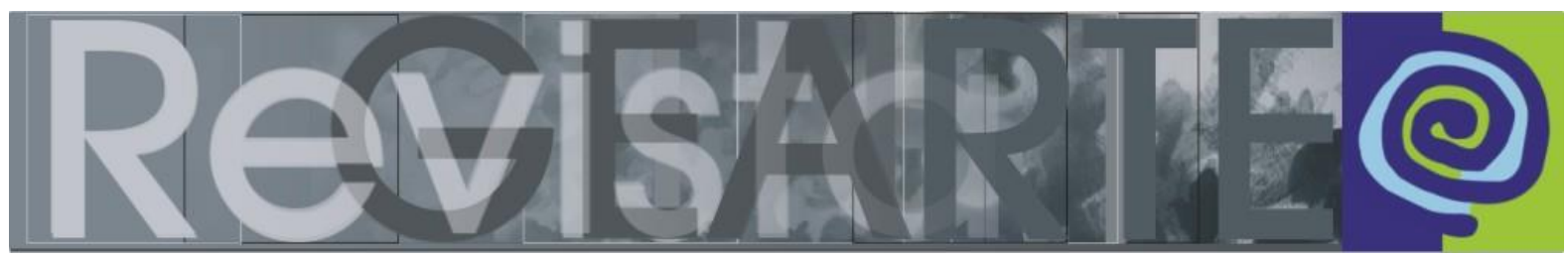

e-ISSN 2357-9854

\title{
Ensayo Visual: Superación de límites, cooperación y sentidos en las prácticas de educación artística
}

\author{
Ricard Ramon Camps (Universitat de València - UV, València, España)
}

\begin{abstract}
RESUMEN - Ensayo Visual: Superación de límites, cooperación y sentidos en las prácticas de educación artística - A través de la construcción de un ensayo visual, se comunica, desde las imágenes, la idea y la necesidad de establecer prácticas pedagógicas en educación artística, que planteen situaciones limitantes, como la pérdida de visión, la falta de movilidad, etc. Situaciones que obligan a establecer estrategias de empatía y cooperación artística hacia la consecución de prácticas artísticas de colaboración, cooperación y compromiso con el otro, reforzando los sentidos y la necesidad de sentirse uno mismo, pero unido al resto, en la producción de una experiencia estética inigualable. Se basa teóricamente en la propuesta pragmatista de Imanol Aguirre (2004) y en los fundamentos filosóficos de Dewey y Shusterman (2000).
\end{abstract}

\section{PALABRAS CLAVE}

Sentidos. Empatía Cooperación. Prácticas artísticas.

RESUMO - Ensaio Visual: Superação de limites, cooperação e sentidos nas práticas do ensino da arte - Através da construção de um ensaio visual, se comunica, a partir de imagens, a ideia e a necessidade de estabelecer práticas pedagógicas no ensino da arte, que abordem situações limites, como a perda da visão, a falta de mobilidade, etc. Situações que obrigam a estabelecer estratégias de empatia e cooperação artística até a consecução de práticas artísticas de colaboração, cooperação e compromisso com o outro, reforçando os sentidos e a necessidade de sentir-se um só, mas unido aos outros, na produção de uma experiência estética inigualável. $O$ ensaio se baseia teoricamente na proposta pragmatista de Imanol Aguirre (2004) e nos fundamentos filosóficos de Dewey e Shusterman (2000).

PALAVRAS-CHAVE

Sentidos. Empatia. Cooperação. Práticas artísticas. 
Las prácticas de educación artística necesitan de estímulos de teatralización, de símbolos que generen expectación y empiecen a despertar los sentidos necesarios para el desarrollo de experiencias estéticas intensificadas. Se trata de construir estrategias basadas en el método del ironista propuesto por Imanol Aguirre (2004) a partir del pragmatismo estético (DEWEY, 2008; RORTY, 1991; SHUSTERMAN, 2000, 2002) que generen estímulos y puntos de partida para el desarrollo de experiencias artísticas y estéticas transformadoras.

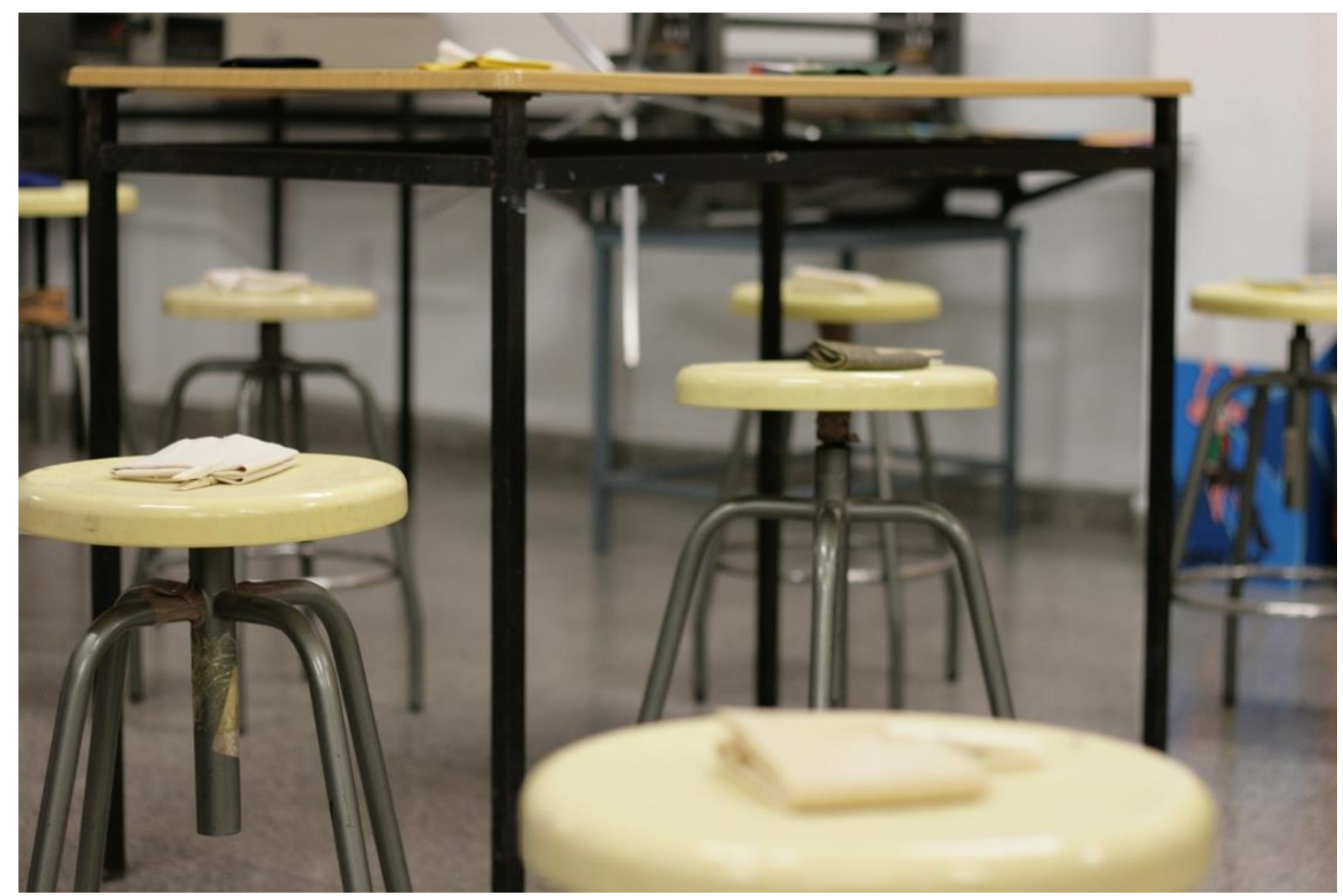


Imponerse límites, generar situaciones que nos remitan a convertirnos en otros, a compartir sus limitaciones, nos permite efectivamente, convertirnos en el otro, nos ayudan a comprenderlo y a comprendernos. Las dinámicas performativas y artísticas, y la búsqueda de nuevas narrativas basadas en la fotografía como recurso de investigación-acción y documentación (MESÍAS-LEMA, 2008), con una finalidad estética y un objetivo pedagógico definen nuevas narrativas de relación entre seres humanos.

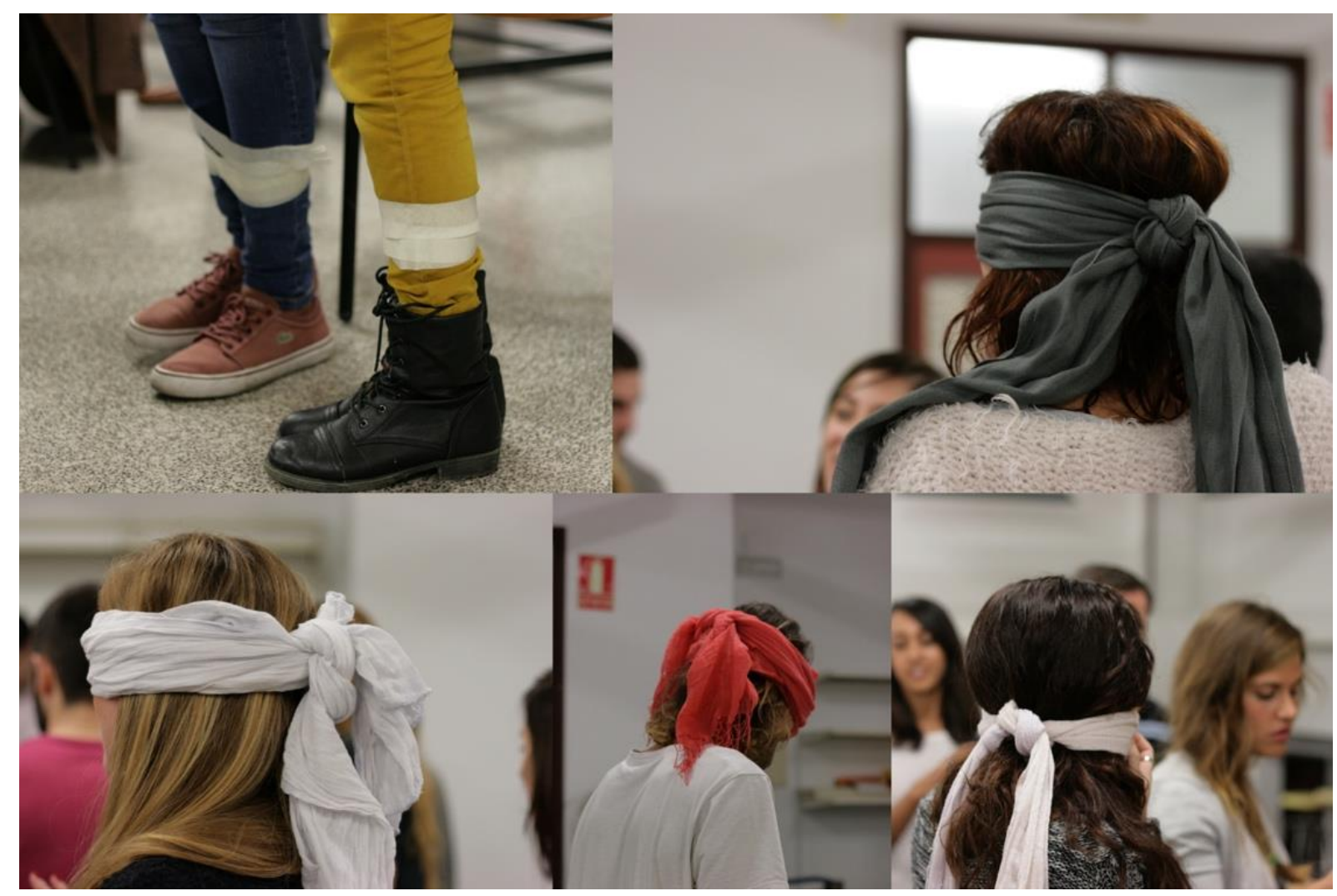


La experiencia de ser mirado sin mirar, de formar parte de algo que puedes escuchar, pero no puedes ver, extrema los procesos sensibles de la participación del alumnado y le permite empatizar de una forma viva y directa con problemáticas de otros seres humanos y sus límites. Jugar a construir límites extremos, intensifica la experiencia estética y la identificación con los otros. El silencio, nos obliga a aprender a escuchar al otro, en un mundo de ruidos, de interferencias constantes y personas que solo gustan de escucharse a sí mismas, obligarse a escuchar es un gran ejercicio pedagógico.

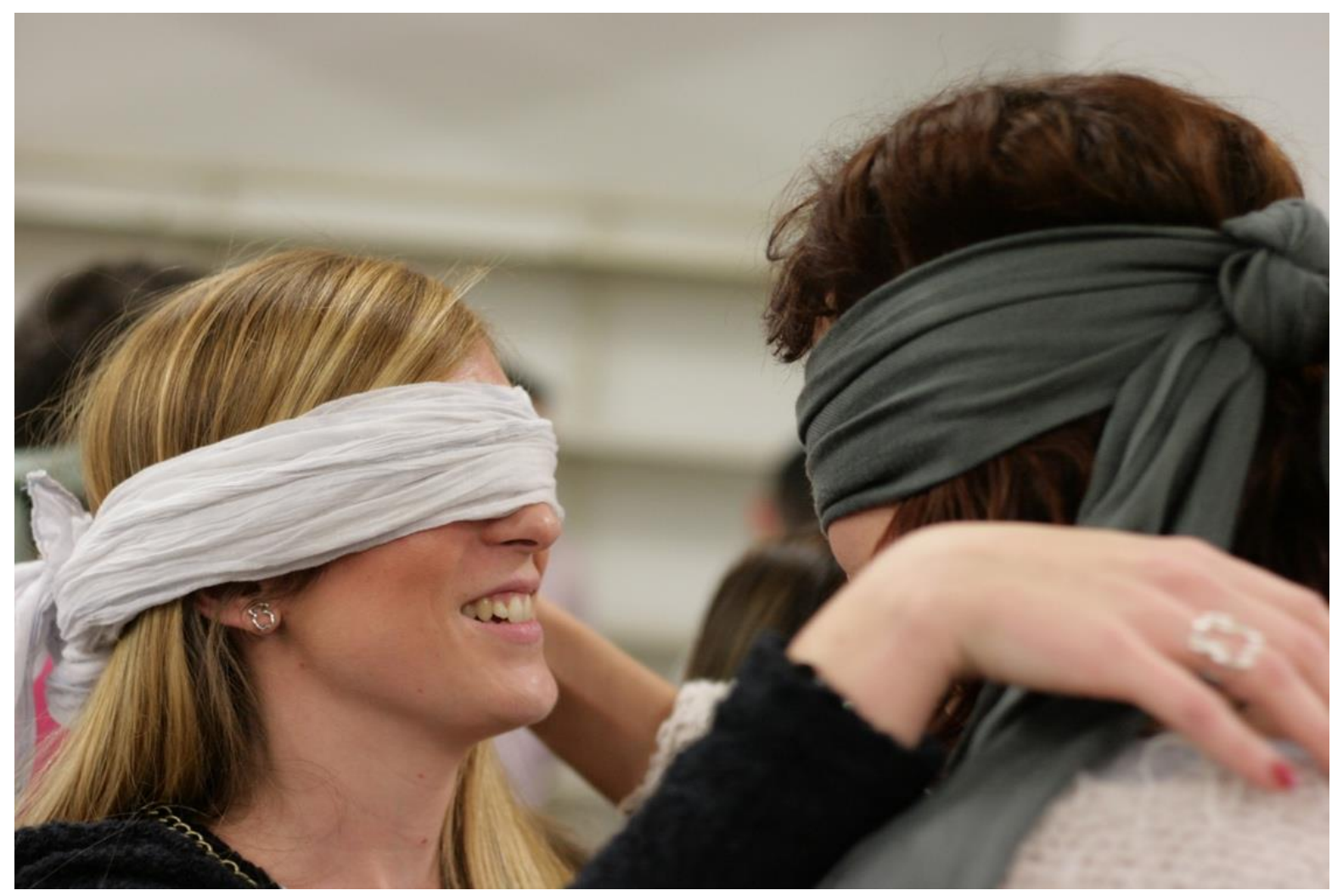


Encontrarse, buscarse, buscar la necesaria ayuda del otro para completarse a uno mismo, a partir de un juego performativo que incita los sentidos perceptivos al máximo. La necesidad de empatía, de tocar, de sentirse acompañado, agudiza el sentido de solidaridad humana. La educación artística construye y activa el ejercicio de un mundo mejor cuando incentiva la necesidad solidaria del necesitarnos unos a otros. Acompañar, guiar, metáfora perfecta del papel del educador y de la educación artística entendida como experiencia, no como instrucción.
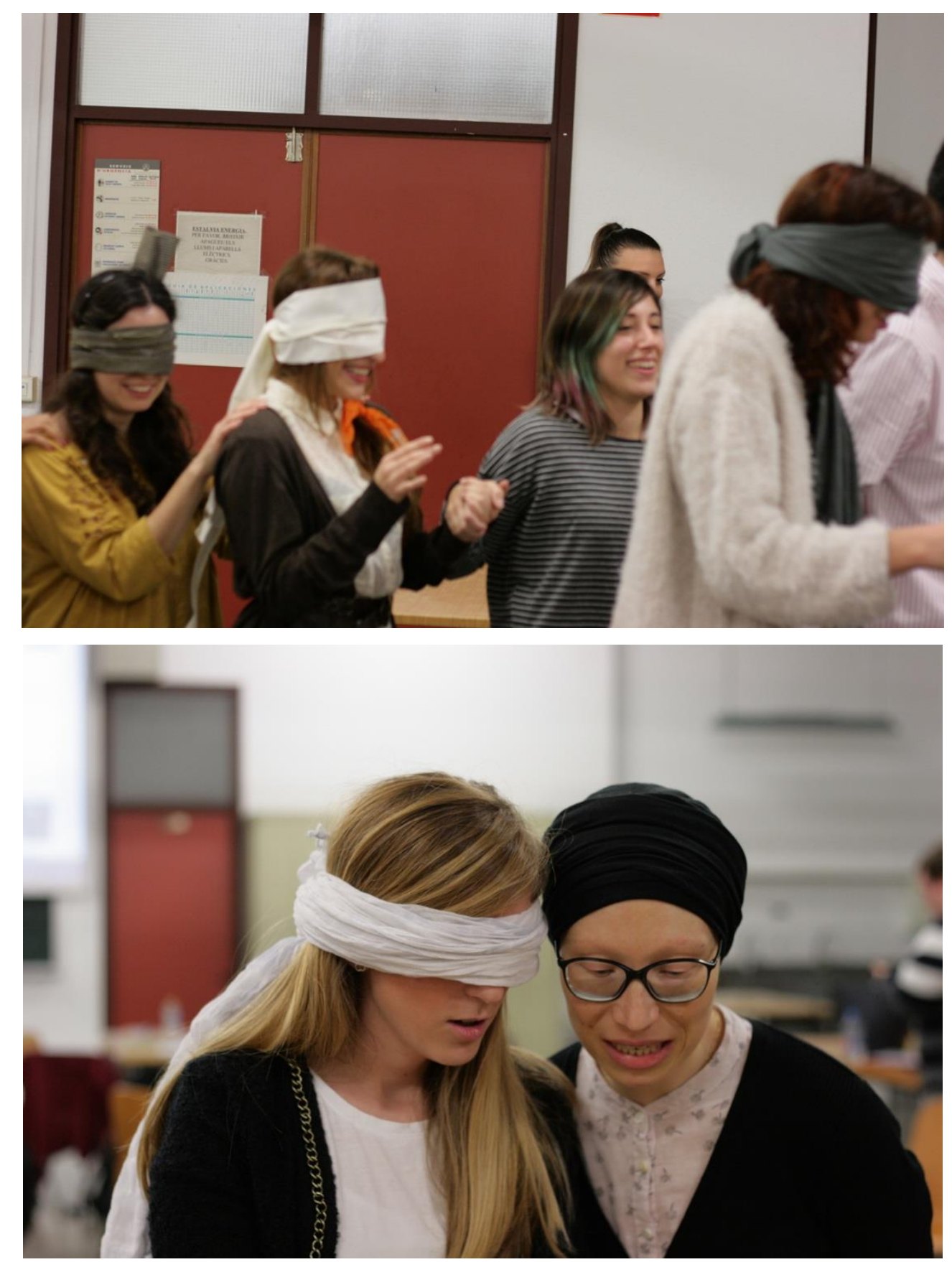
Escuchar, compartir, sentir al otro como necesario, entender que el aprendizaje es algo que hago con el otro y que no puedo recibir sin el otro. Construir y crear en conjunto a pesar de las limitaciones, como un organismo de seres humanos dirigidos por el objetivo de la colaboración y la búsqueda de la creación artística. Entendemos que el proceso de creación colectiva, es una hermosa obra de arte en sí misma. Nos integramos y pasamos a formar parte de la obra, somos la obra, aprendemos y creamos a la vez y aprendemos que, crear junto al otro y con el otro, es una experiencia humana intensa y necesaria en nuestro proceso de formación.

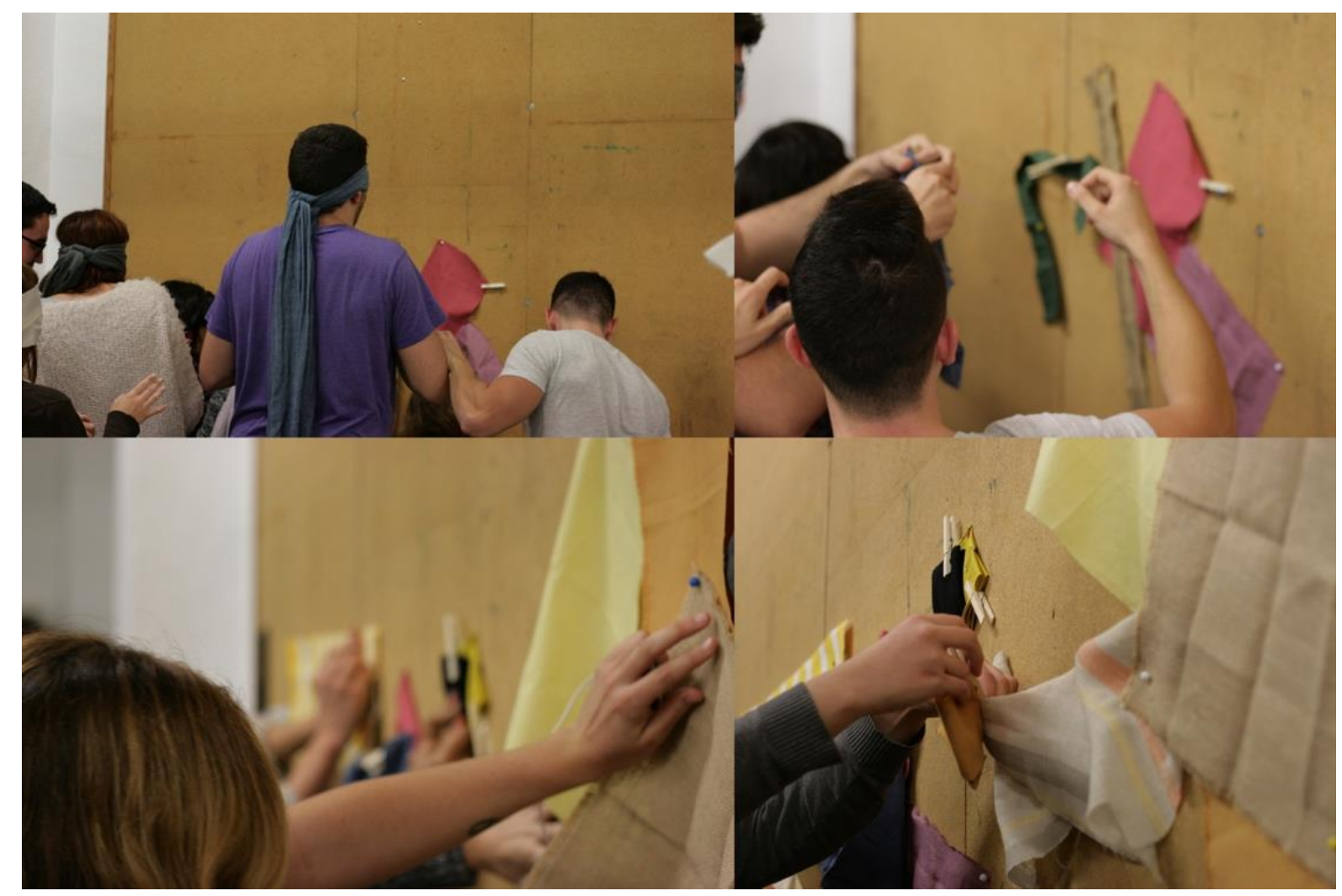




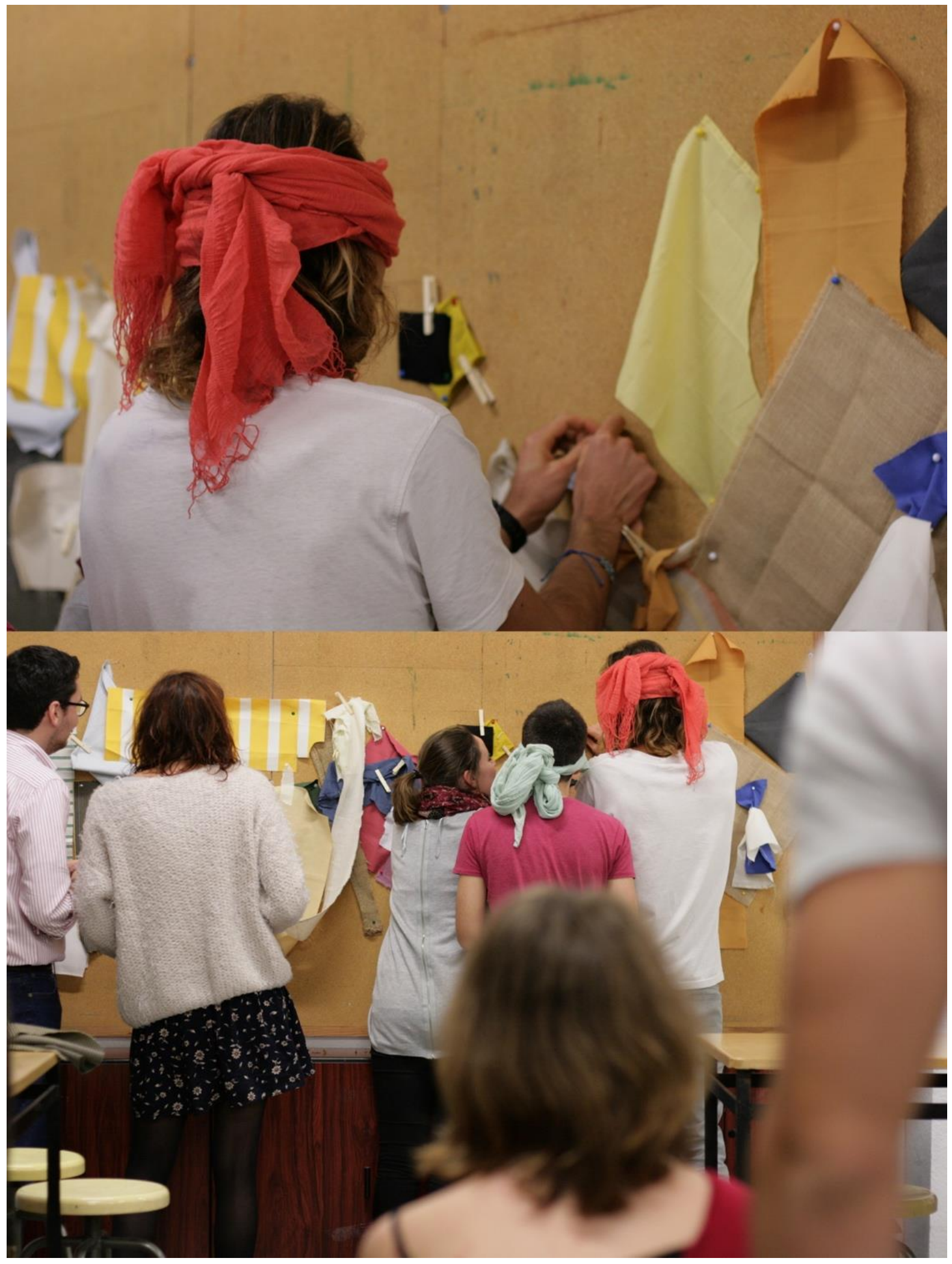




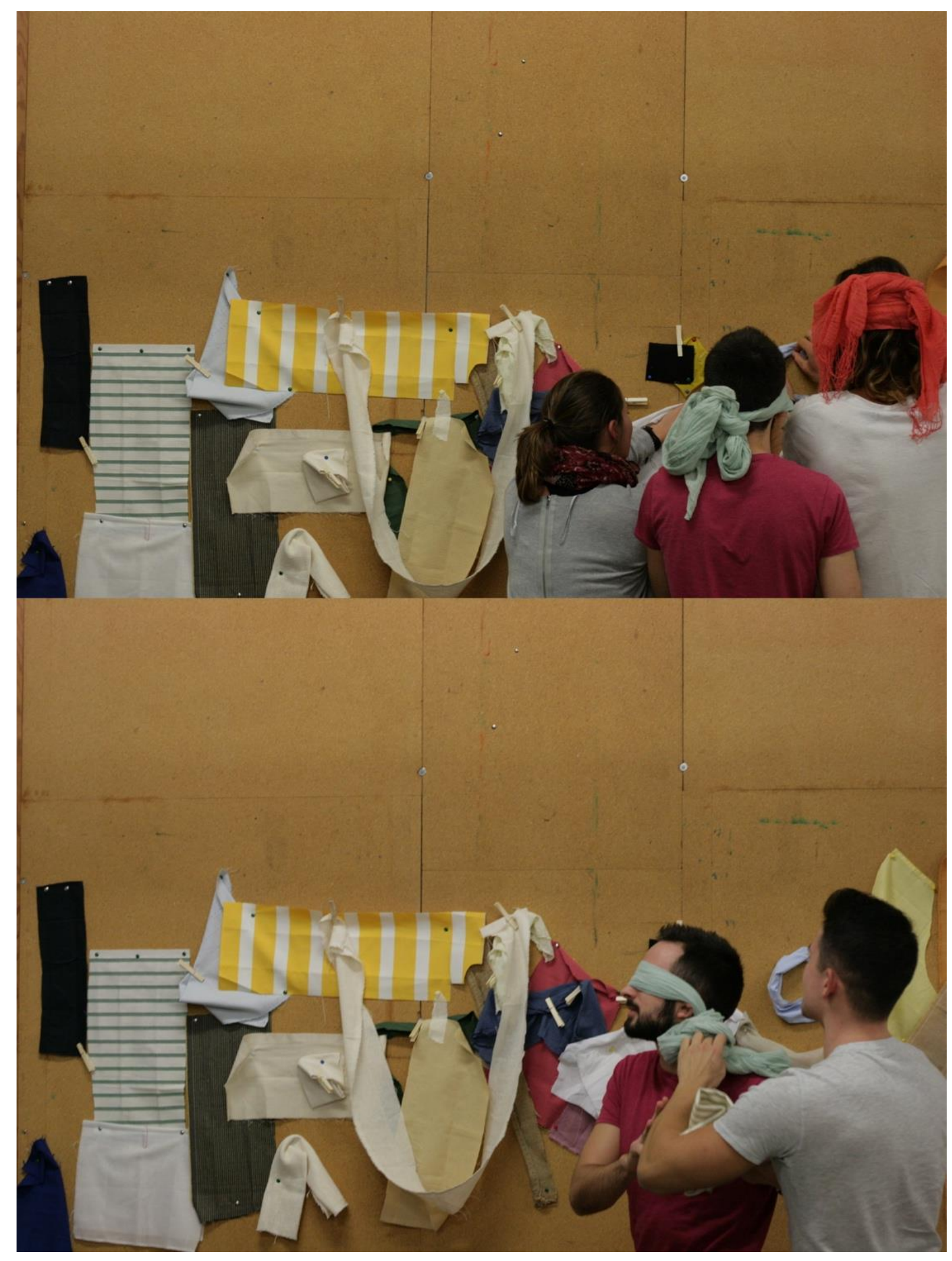


La cooperación artística permite superar límites, pero especialmente permite construir discursos estéticos conjuntos profundamente hermosos, tanto en su propia ejecución y práctica como en su desarrollo final como trabajo cooperativo. Como conclusión, ninguna imagen es tan potente y clara como una sonrisa para definir la experiencia artística educativa.

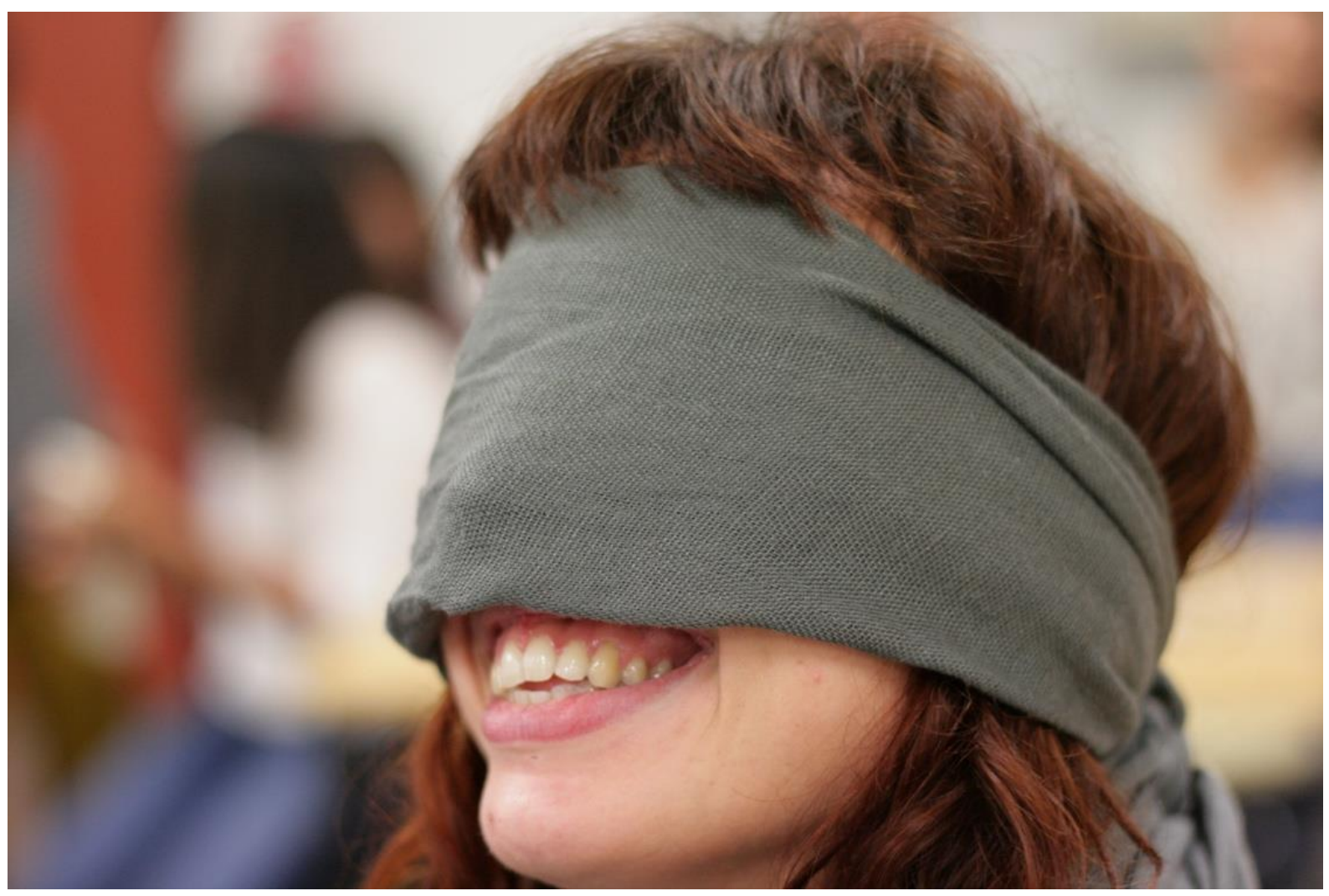




\section{Referencias}

AGUIRRE, Imanol. Beyond understanding of visual culture: a pragmatist approach to aesthetic education. Journal of Art and Design Education, v. 23, n. 3, p. 256-269, 2004. Disponível em: <http://onlinelibrary.wiley.com/doi/10.1111/j.1476-8070.2004.00405.x/full> Acesso em: 11 jan. 2017.

DEWEY, John. El arte como experiencia. Barcelona: Paidós, 2008.

MESÍAS LEMA, José María. El murmullo de la circulación de la sangre: la fotografía como medio narrativo en Educación Artística. Arte, Individuo y Sociedad, v. 20, p. 69-94, 2008. Disponível em: <https://revistas.ucm.es/index.php/ARIS/article/view/ARIS0808110069A > Acesso em: 15 maio 2017.

RORTY, Richard. Contingencia, ironía y solidaridad. Barcelona: Paidós, 1991.

SHUSTERMAN, Richard. Performing live: aesthetic alternatives for the ends of art. Ithaca, Nova lorque: Cornell University Press, 2000.

SHUSTERMAN, Richard. Estética pragmatista: viviendo la belleza, repensando el arte. Barcelona: Idea Books, 2002.

\section{Ricard Ramon Camps}

Profesor de educación artística, artista visual y escritor. Profesor en la Facultat de Magisteri de la Universitat de València (España). Investigador del Instituto Universitario de Creatividad e Innovaciones Educativas. Codirector del Postgrado Experto Universitario en Fallas y Creatividad. Doctor en Filosofía y Ciencias de la Educación en el área de Estética y Teoría de las Artes, Licenciado en Bellas Artes, Licenciado en Historia del Arte y Master en Gestión Cultural. Miembro del Grupo CREARI de Investigación en Pedagogías Culturales (GIUV2013-103).

E-mail: ricard.ramon@uv.es

Currículo: https://uv.academia.edu/RicardRamon 